\section{AB0242 DELAY IN DMARD INITIATION IN PATIENTS NEWLY DIAGNOSED WITH RHEUMATOID ARTHRITIS: AN ANALYSIS OF UNITED STATES MILITARY HEALTH SYSTEM BENEFICIARIES}

L. Kimsey ${ }^{1}$, J.S. Weissman ${ }^{2}$, A. Patel ${ }^{3}$, A. Drew ${ }^{1}$, T. Koehlmoos ${ }^{3}$, J.A. Sparks ${ }^{2}$ ${ }^{1}$ Georgia Southern University, Statesboro; ${ }^{2}$ Brigham and Women's Hospital, Harvard Medical School, Boston; ${ }^{3}$ Uniformed Services University of the Health Sciences, Bethesda, USA

Background: Prompt initiation of disease-modifying antirheumatic drugs (DMARDs) is recommended for patients diagnosed with rheumatoid arthritis (RA) to improve symptoms and prevent disease progression, but treatment delays may still occur.

Objectives: To investigate predictors and temporal trends for delay in DMARD initiation among patients with incident RA in the United States.

Methods: We performed a longitudinal cohort study using administrative data from the United States military's TRICARE program (2007-2012). TRICARE beneficiaries, who are demographically similar to the US, include active/retired military members, spouses, and dependents and receive care in military or civilian settings. We identified incident RA cases using billing codes and initial DMARD receipt using prescription fill date. We quantified the time between RA presentation and initial DMARD receipt, temporal changes in time to treatment over the study period, and investigated predictors of treatment delay (>90 days) using logistic regression.

Results: We identified 16680 patients with incident RA that were later prescribed DMARDs. Mean age was 47.2 (SD 13.5) years, $77.6 \%$ were female, and $76.5 \%$ were spouses/dependents of the military sponsor. The mean time from initial RA presentation to first DMARD prescription was 125.3 days (SD 175.4). Over onethird $(35.6 \%)$ of incident RA patients experienced treatment delay ( $>90$ days between presentation and DMARD receipt). Time to DMARD initiation was shorter in later years of the study (mean 144.7 days in 2007; 109.7 days in 2012). Patients prescribed opioids between RA presentation and initial DMARD receipt had 4-fold increased risk for delay in initial DMARD (OR 4.07, 95\% Cl 3.78-4.37). Patients prescribed opioids had mean time to DMARD of 212.8 days (SD 207.4) compared to mean of 77.3 days (SD 132.3) for those who did not use opioids $(p<0.0001)$. Use of prescription NSAIDs between initial RA presentation and DMARD initiation was also associated with delay (OR $3.32,95 \% \mathrm{Cl} 3.09-3.57)$. Men were less likely than women to experience delay (OR $0.89,95 \% \mathrm{Cl} 0.82-0.98$ ).

Abstract AB0242 - Table 1. Odds ratios for delay in DMARD initiation (>90 days) after initial presentation for incident rheumatoid arthritis $(n=16,680)$

\begin{tabular}{|c|c|c|}
\hline & $\begin{array}{l}\text { Unadjusted OR } \\
(95 \% \mathrm{Cl})\end{array}$ & $\begin{array}{c}\text { Multivariable* OR } \\
(95 \% \mathrm{CI})\end{array}$ \\
\hline \multicolumn{3}{|l|}{ Sex } \\
\hline Female & 1.00 (Ref) & 1.00 (Ref) \\
\hline Male & $0.81(0.75-0.87)$ & $0.89(0.82-0.98)$ \\
\hline \multicolumn{3}{|c|}{ Year of index date } \\
\hline 2007 & 1.00 (Ref) & 1.00 (Ref) \\
\hline 2008 & $1.29(1.16-1.44)$ & $1.28(1.13-1.44)$ \\
\hline 2009 & $0.91(0.81-1.01)$ & $0.90(0.80-1.02)$ \\
\hline 2010 & $0.81(0.73-0.91)$ & $0.84(0.74-0.95)$ \\
\hline 2011 & $0.77(0.69-0.86)$ & $0.78(0.69-0.88)$ \\
\hline 2012 & $0.79(0.71-0.88)$ & $0.78(0.69-0.89)$ \\
\hline \multicolumn{3}{|c|}{ NSAID use between index date and } \\
\hline \multicolumn{3}{|c|}{ DMARD initiation } \\
\hline No & 1.00 (Ref) & 1.00 (Ref) \\
\hline Yes & $4.02(3.76-4.30)$ & $3.32(3.09-3.57)$ \\
\hline \multicolumn{3}{|c|}{ Opioid use between index date and } \\
\hline \multicolumn{3}{|c|}{ DMARD initiation } \\
\hline No & 1.00 (Ref) & 1.00 (Ref) \\
\hline Yes & $4.74(4.42-5.07)$ & $4.07(3.78-4.37)$ \\
\hline
\end{tabular}

*The multivariable model was also adjusted for age, US region, care setting (military or civilian), military rank of sponsor, number of clinic visits prior to index date, and Charlson Comorbidity Index.

Conclusions: In this large US nationwide study, delays in initial DMARD receipt after incident RA were common but time to treatment improved in later years of the study. Avoiding opioid use may decrease delay in initiating DMARDs during this vulnerable period when pain and disease activity are often most pronounced. Disclosure of Interest: None declared

DOI: 10.1136/annrheumdis-2018-eular.3925

\section{$\mathrm{AB} 0243$ \\ REAL WORLD CLINICAL TRIAL COMPARING THE PATIENT REPORTED OUTCOMES MEASUREMENT INFORMATION SYSTEM SHORT FORMS AND PROFILES TO CDAI DISEASE CLASSIFICATION IN RHEUMATOID ARTHRITIS PATIENTS}

J. Curtis ${ }^{1}$, S. Schwartzman ${ }^{2}$, S. Kafka ${ }^{3}$, D. Parenti ${ }^{3}$, S. Black ${ }^{3}$, S. Xu ${ }^{4}$,

W. Langholff ${ }^{5}$, C.O. Bingham III ${ }^{6}{ }^{1}$ U of Alabama, Birmingham; ${ }^{2}$ Weill Cornell

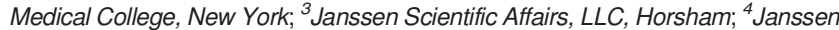
Research and Development, LLC, Spring House; ${ }^{5}$ Janssen Research and Development, LLC, Horsham; ${ }^{6}$ Johns Hopkins U, Baltimore, USA

Background: Pt reported outcomes (PROs) play a role in disease evaluation, therapeutic assessment and care of RA pts. The Pt Reported Outcomes Measurement Information System (PROMIS [P]) questionnaires developed by NIH have been used in RA clinical practice and studies. ${ }^{\text {Brtlett }} 2015$ AWARE (Comparative and Pragmatic Study of Golimumab Intravenous [IV] Versus Infliximab in RA) is a noninterventional, multi-centre US-based, study of golimumab IV (GLM) vs. infliximab (IFX) in RA and will assess disease activity (DA) and use PROs.

Objectives: 1. PRO assessments of Pt response to treatment using PROMIS-29 Profile v2.0 (P29v2), P Pain Interference Short Form-6b (PISF) and P Fatigue Short Form-7a (FSF), and Clinical DA Index (CDAI), and 2. assess relationship between PROMIS T-score and CDAl category.

Methods: AWARE is a 1200 adult pt study enrolling pts on initiation of treatment w/GLM or IFX. We report an interim analysis (IA) of 747 pts' baseline PROMIS questionnaire and CDAI scores. PROMIS results are normalised to the US population, reported as a "T-score" (mean $=50, S D=10)$ w/higher scores indicating more of the trait measured. PROMIS T-scores were compared between High DA (HDA) w/Moderate DA (MDA), low DA (LDA) and remission. Data shown are mean $\pm S D$. Statistical testing compared T-scores across CDAl categories using ANOVA for these data (before drug admin). Data from GLM and IFX pts are combined.

Results: Mean baseline CDAI score was $32.5 \pm 15.4$, w/71.7\% of pts in HDA, $22.5 \%$ in moderate MDA, $5.2 \%$ in LDA and $0.7 \%$ in remission. PROMIS T-scores were compared to $4 \mathrm{CDAl}$ categories. HDA Pt T-scores were $\left({ }^{*}, \mathrm{p}<0.05\right)$ different from those of MDA, LDA and Remission pts (except between HDA and remission for Anxiety, Depression and Sleep Disturbance domains).

Abstract AB0243 - Table 1

\begin{tabular}{|c|c|c|c|c|c|}
\hline & $\begin{array}{l}\text { All Patients } \\
\text { (n=672-682) }\end{array}$ & $\begin{array}{l}\text { Remission } \\
\text { CDAIS2.8 } \\
\text { (n=5) }\end{array}$ & $\begin{array}{l}\text { LDA } \\
2.8<C D A I \leq 10 \\
(n=38)\end{array}$ & $\begin{array}{l}\text { MDA } \\
10<C D A I \leq 22 \\
(n=165)\end{array}$ & $\begin{array}{l}\text { HDA } \\
\text { CDAl }>22 \\
(n=526)\end{array}$ \\
\hline Physical function & $37.9 \pm 6.6$ & $47.5 \pm 5.7$ & $45.0 \pm 7.6$ & $40.0 \pm 6.7$ & $36.6 \pm 5.9^{*}$ \\
\hline Anxiety & $53.8 \div 10.4$ & $45.2 \pm 6.7^{4}$ & $47.7 \pm 8.6$ & $51.3+10.0$ & $55.2 \pm 10.3^{*}$ \\
\hline Depression & $52.5 \pm 10.3$ & $42.6 \pm 3.6^{11}$ & $45.9 \pm 6.5$ & $49.4 \pm 9.8$ & $54.0 \pm 10.3^{*}$ \\
\hline Fatigue & $58.8 \pm 9.9$ & $42.3 \pm 5.4$ & $49.7 \pm 9.7$ & $55.6+9.2$ & $60.8 \pm 9.4^{*}$ \\
\hline Sleep Disturbance & $55.5 \pm 8.7$ & $48.2 \pm 13.6^{n}$ & $51.5 \pm 7.9$ & $53.2 \pm 8.4$ & $56.7 \pm 8.6^{*}$ \\
\hline $\begin{array}{l}\text { Ability to participate in } \\
\text { Social Roles \& Activities }\end{array}$ & $43.2 \pm 8.6$ & $57.3 \pm 7.6$ & $50.8 \pm 8.5$ & $45.9 \pm 8.5$ & $41.6 \pm 8.0^{\circ}$ \\
\hline Pain Interference & $63.5 \pm 7.7$ & $46.9 \pm 7.2$ & $53.9 \pm 8.4$ & $60.1 \pm 7.7$ & $65.4 \pm 6.5^{*}$ \\
\hline Fatigue Short Form $7 \mathrm{a}$ & $59.3 \pm 8.5$ & $46.7 \pm 8.8$ & $51.6 \pm 9.0$ & $56.2 \pm 7.5$ & $61.0 \pm 8.1^{*}$ \\
\hline $\begin{array}{l}\text { Pain Interference Short } \\
\text { form } 6 \mathrm{~b}\end{array}$ & $62.5 \pm 7.6$ & $45.9 \pm 7.5$ & 53.9:9.3 & $59.3 \pm 5.6$ & $64.3 \pm 6.4^{*}$ \\
\hline $\begin{array}{l}\text { Pain Intensity } \\
\text { (scored 0.10 scale) }\end{array}$ & $6.0 \pm 2.2$ & $1.6 \pm 2.6$ & $3.5 \pm 2.3$ & $5.1 \pm 2.2$ & $6.6 \pm 1.9^{*}$ \\
\hline
\end{tabular}

Conclusions: Our interim findings demonstrate the feasibility of using PROMIS short forms and profiles to evaluate RA Pts in clinical trials. These results confirm the domain validity of PROMIS measures according to CDAI DA category. PROMIS measures show the range of impact across multiple domains of physical, emotional, and social health experienced by RA Pts.

Disclosure of Interest: J. Curtis Grant/research support from: Janssen Scientific Affairs, LLC, S. Schwartzman Grant/research support from: Janssen Scientific Affairs, LLC, S. Kafka Employee of: Janssen Scientific Affairs, LLC, D. Parenti Employee of: Janssen Scientific Affairs, LLC, S. Black Employee of: Janssen Scientific Affairs, LLC, S. Xu Employee of: Janssen Research and Development LLC, W. Langholff Employee of: Janssen Research and Development, LLC, C. Bingham III Grant/research support from: Janssen Scientific Affairs, LLC DOI: 10.1136/annrheumdis-2018-eular.1800 